\title{
1. Introduction: the big challenges
}

\subsection{INTRODUCTION}

Welfare states have been said to be in crisis for a long time since the golden growth period - for example until the start of the first oil price increase in the early 1970s. This crisis has been argued to be the case due to the lack of an ability to finance the public sector, and changes in ideology, ideas, preferences and demographic transitions towards more greying societies. Some classical works include Mishra (1984), O'Connor (1973) and OECD (1981). For a more recent overview, see Greve (ed.) (2012). Thus, challenges and crises of welfare states are, as such, not a new issue or a new idea. Neither is the debate on retrenchment, recalibration, etc. with regard to the development of welfare states; for a now classical overview see Starke (2006). Ideas also play a central role in the route welfare states take; for a seminal paper see Béland (2005), and for a recent overview, see Béland and Powell (2016), and further in Chapter 7.

The expected change in demography and the possible pressure on welfare state spending is an ongoing discussion, cf. European Commission and the Social Protection Committee (2014). Central to this has even been a debate about whether these demographic changes could imply a lack of manpower. For example, in a report on Germany's economy of 5 April 2016, a lack of manpower and the option that migrants could plug the gap was the central message. ${ }^{1}$ The possible impact on the pension system and the need to stay longer in the labour market have been other central elements in the development and discussions of many welfare states, especially in Europe. As late as February 2016, the possible pressure on public spending due to a change in demography was central in a paper from the Organisation for Economic Co-operation and Development (OECD) (Dutu and Sicari, 2016), and also how higher efficiency in public sector spending could be achieved. Although it is natural, constantly, to look for higher efficiency in the delivery and use of 
public sector spending, it seems that the possible pressure on welfare states due to demographic transition is only one, and perhaps not the strongest, of the challenges for welfare states. Another, and perhaps even more dramatic, challenge - and a central theme in this book - is the consequence of new technology on the number and quality of jobs on the labour market, and implicitly thereby also on welfare states.

A number of presentations and analyses about the possibilities of using new technology - from robots and self-driving cars to the ability to use Big Data to solve complex problems - have been put forward in recent years. As a consequence of the expected dramatic changes in the way we will be able to produce and consume goods compared to in the past, authors have tried to estimate the impact on labour markets and on possible job losses (Frey and Osborne, 2013); see additionally in Chapters 2 and 3. This first chapter outlines some of the hypotheses on how the changes will influence especially labour markets and welfare states in Europe, and via this, it indicates why this might have a profound impact on the understanding of the possible increase in dualisation on labour markets. Further, this chapter outlines the content of the rest of the book.

The use of new technology might also imply a possible reduction in public sector spending by reducing the need for labour due to increased productivity, and thereby reduce the pressure on welfare states. This might, for example, be the case with welfare technology (Greve (ed.), 2017). Naturally, this also reduces the overall need for labour, and there might be other possible negative impacts of the perceived quality of the service by, for example, less human contact. This is not, however, pursued further in this book.

If technological development wipes away many jobs in a short period of time, then many people will have difficulties continuing in the labour market, and many young people wanting to enter the labour market might not be able get a foothold in it. The argument is not that this will be an issue for all; however, dramatic changes in the labour market imply that certain competences will no longer be in demand, and therefore that some people will not have the qualifications for those jobs that are or will be available. Given that there will also be fewer unskilled jobs, this will imply that the unskilled, especially, are in a position where they will not be able to find a job. Even if they can find a job, this might be at a very low wage level, and therefore they have a high chance of becoming working poor. For 
example, even when working full-time their income will be below the "at risk of poverty line", such as the 60 per cent of median income as used in Eurostat data. A new issue such as underemployment is also integrated into the analysis.

This development is in stark contrast with the movement in many countries towards a work-first approach (Taylor-Gooby et al., 2015) as there might not be a need for such an approach, or it might actually be even more difficult for many to secure a job. This is therefore also in contrast to the tendency towards recommodification in many welfare states in recent years (Shahidi, 2015). The work-first approach and the risk of the lack of a sufficiently large labour force have been more in focus than the impact on technological development. This can be illustrated by the fact that a book published in 2015 on the future of labour in Europe touched upon technology only to a limited extent, and had a stronger focus on where there might be new jobs and whether migration could be part of the solution if there is too little manpower (Beblavy et al., 2015).

Not only will there be consequences on the labour market, but there will also be a risk of lower overall economic activity (those without jobs have no or limited buying power, and are dependent on the social security system), and governments might lack the ability to finance welfare states. Thus the generosity and size of welfare states might be endangered, and the risk of a financial crisis of welfare states can further imply that the options and possibilities of ensuring coherent societies will be reduced. Thus the need for new ways of helping to have stable and well-functioning societies might be an emerging trend.

Therefore, this book looks into how these changes might have an impact on welfare states and labour markets, and discusses the possible outcome of these changes. Methodologically, by the use of comparative data, the book tries to illuminate whether the changes will be the same in all types of welfare states, or whether some are more prepared than others to cope with the possible changes. Dependent on data availability, the focus is on the United Kingdom (liberal model), Denmark and Sweden (Nordic model), Germany and France (Central European model), Spain and Italy (Southern European model) and, from Eastern Europe, the Czech Republic and Poland, with EU28 as the reference background. When using OECD data, again as far as possible, data for another liberal welfare state, the United States, is included. In order to present a broader picture, 
in several places more countries from the European Union (EU) are included in the data.

One hypothesis analysed in the book is whether or not there will be a stronger pressure in the more universal welfare states compared to the liberal and continental welfare state types. As part of these changes include forward-looking perspectives, the hypothesis is not tested through classical quantitative analysis, but deducted from analysis and description of ongoing and expected changes, and how these can have repercussions and impacts on different kinds of welfare states.

Recent years have seen the possible beginning of many of these changes on the labour market as outlined above, leading to more precarious situations for those wanting to have an income and a job. The following short depiction and presentation of data refer to EU28 and are from Eurostat's database - accessed in July and November 2016.

The number of people in involuntary temporary employment has increased from 7.2 per cent in 2003 to 8.9 per cent in 2015 - or, to put it another way, around one in every 12 people is now working in an involuntary temporary job, and at risk of losing that job at short notice precisely because it is temporary. At the same time, temporary employees have increased as part of the total number of employed people from 12.6 per cent in 2003 to 14.1 per cent in 2015 - or, every seventh person is now in a temporary job. This might not in itself be a problem if it is easy to move from one job to another without too long a gap between jobs, but it can also point to a weaker position in the labour market for many employees.

Some see this as a positive development, increasing the option of choosing how much time is spent in work. This development has even been termed the rise of the supertemp (https://hbr.org/2012/05/ the-rise-of-the-supertemp, accessed 15 September 2016), but it is also acknowledged that there might be a need for clear rules in relation to ensuring access to certain services, such as the health care system in the US. This indicates that, for some, temporary jobs and flexibility have advantages; however, it seems to be mainly for a few highlyskilled people. Thus, another hypothesis is that this development will increase the inequality and social divide in societies.

There is not only an increase in temporary jobs - there is also an increase in people working in part-time jobs. This has risen from 15.3 per cent in 2003 to 19.1 per cent in 2015. This again can reflect a choice, and in many countries it is a way to combine work and family life, but for others part-time work implies a risk of being working 
poor and not being able to participate as much as one would like in other activities. At the same time, there has been an increase in underemployed part-time workers. This indicates that although parttime work can help in combining work and family life, it is not for the full preferred number of working hours.

Further, available data do not include the working hours of the self-employed, and, as analysed later, being self-employed might not currently, and perhaps even less in the future, imply what we today understand as being fully employed.

The employment rate of low-skilled people has also declined (from 55.5 per cent in 2003 to 52.6 per cent in 2015), which is another indicator that there is an increasing number of people with difficulties in securing, or continuing to have, a foothold on the labour market. At the same time, the unemployment rate has risen. Partly this reflects economic development since the financial crisis, but also that we might be in a time of jobless economic growth. From 2003 to 2015 there was negative growth in the number of jobs in four separate years, and overall since the financial crisis there are still fewer people in jobs in the EU in 2015 than before the crisis began.

This short depiction of some of the developments in the labour market is the first indication of the growing problems in the labour market. Problems - as the book shows - which have a high risk of being many times worse in the years to come when enacting and implementing the use of new technology, with potentially severe repercussions on welfare states, equality and the degree of cohesion in societies.

\subsection{OVERVIEW OF THE BOOK}

After this short introductory chapter the book, in different ways, revolves around technology, the labour market and welfare states. History is full of discussions of the risk of technological unemployment, which is the focus in Chapter 2. A short history going back to Gutenberg and the Luddites paints the picture of the fact that, on the one hand, this risk has always been there, and, on the other hand, that the fight against technological progress has always been lost, in the sense that new technology has been implemented and used despite the fight against it. Therefore, the question is more how to embrace new technology and use the options it creates, while at the 
same time also trying to ensure options for those who perhaps are less strongly positioned in the labour market, including the ability to use information technology (IT) and new technology. New technology might make goods cheaper and might thereby enable people to buy more - thus, in classical economic theory, increasing the demand for labour. However, new technology, including the use of robots which never get tired, can also produce more efficiently; therefore, this will reduce the demand for labour in the years to come unless new types of production or services are created and, as a consequence, new types of jobs will develop. Elements of this form part of the analysis in Chapter 3.

Chapter 3 also focuses on the development of Big Data, and the use of the internet and robots as emerging trends (some of which have been in existence for some time). There might be stronger and faster development in this area than previously, implying that classical production presumably will be wiped away, and that in several areas labour, even if wages are moving towards zero, will not be able to compete with the speed and efficiency of new technology, including the use of robots. Therefore, as has been the case throughout history, not only might existing jobs become redundant, but also, presumably, fewer new jobs will be created. This new development is a pressure not only on low-skilled jobs, but also increasingly on high-skilled jobs within, for example, the financial sector, higher education, law and medicine. This also questions the hypothesis of the hollowing out of the middle of the labour market, albeit that this is still a risk, see also further in Chapter 5 . The use of new technologies reduces the measurable growth in gross domestic product (GDP), as the marginal cost of producing one extra unit moves towards zero. For example, this is the case in the cost of a download of a picture on the internet, which is often zero or close to zero. This is exacerbated by the development of the collaborative or sharing economy, and this is part of the central emphasis in Chapter 4.

Part of what new technology can offer is alternative ways of producing and using different goods and services, which is also the focus of Chapter 4. The sharing economy or the collaborative economy are just two of the many names for a new division of production between work and/or capital of goods and services, which is also the focus of this chapter. This is, partly, the use of IT as a means of developing new market platforms to sell goods and especially services and, partly, a way of sharing in order to consume less and be less in need 
of producing and buying new goods and services. If consumption is reduced this will also influence the number of jobs. The sharing of jobs using new platforms - such as the development of software for IT, different types of consultancy, call-centres, accounting, etc. implies that only those willing to provide work for the lowest amount of pay will get the jobs. Further, jobs in many of these areas will not be restricted by national borders, but will be open to international competition. For some, who expect to earn money by sharing (flats, cars, etc.), this will also open up a more precarious and unstable situation thereby reducing their economic and social security. Selfemployment in a digital economy can thus also be a smokescreen for, in reality, having some form of work and - for a large part of the labour force - being without sufficient household income, despite not being registered as unemployed, thereby reducing the validity of the data on unemployment figures.

Possible consequences of this are the moves towards a dual labour market, which is the point of reference in Chapter 5. For a long time here has been discussion on insiders versus outsiders within labour markets, which has been about the possible impact of insiders demanding higher wages thereby preventing outsiders from entering the labour market. Even though the labour market seems to be moving towards a dual labour market, this is presumably less so in the historical sense of insiders versus outsiders, but more in line with the fact that jobs in the middle of the labour market will disappear, whereas some low-skilled jobs will still exist, although they will also be seriously threatened by the use of new technology. In addition, those remaining will run the risk of becoming what has been termed the working poor. In the area of high-skilled labour there will also be a reduction of jobs. In the middle of the job ladder there might still be caring jobs - especially of children in day care and elderly care in homes for the elderly where robots are less likely to reduce the number of jobs. In other service areas, technology will also imply a reduction in the number of jobs. This chapter outlines possible changes based on an analysis of changes in job structure from within by different welfare state regimes in selected European countries.

The question thus arises as to whether these changes will imply the end of labour market organisations, as we know them today, as strong players, which is the focus of Chapter 6. In many countries there has already been a decline in the membership of trade unions and a weakening of employees' organisations. This expected development 
will, presumably, continue to reduce trade union membership, given the increase in the number of "self-employed", people using the sharing economy, and short-term contract workers, etc. Thus collective agreement as stabilisers on the labour market - and helping to ensure a decent wage income in order to reduce the risk of the working poor - might be wiped away, implying a risk of more unstable labour markets and rising inequality in many countries. Especially in the northern part of Europe, trade unions have also been challenged by the free movement of labour, including the so-called selfemployed, and in Chapter 8 a further focus on migration is presented. Consequently, in many welfare states, including corporatist types, the stable functioning of steering societal development by integrating organisations within the labour market in decision making and administration is under threat. Finally, this chapter concentrates on the possible impact on the stability of the labour markets.

From these discussions, the book moves on to analyse and discuss, in Chapter 7, whether welfare states are prepared and whether some are better prepared than others. If fewer people are employed in the labour market, this will imply a risk of lower tax revenue to the public sector and an increase in the number of people dependent on the social security system. Together, this implies a strong pressure on the ability to finance welfare states and to cover those who have previously been covered by employers' social security contributions. If wage income falls, then consumption will also go down - and then, presumably, overall economic activity will also fall. This will increase the need for new ways of redistributing income and consumption possibilities in many countries. Naturally, the use of new technology can imply both the possibility of cheaper delivery of services - for example, welfare technology may help in the area of long-term care - and also a reduction in the number of jobs, which will imply more segregated labour markets. This chapter also includes a debate on guaranteed minimum income as one possible way of approaching the problem. Finally, new technology will challenge the existing ways of measuring society's development, as we will be able to have more consumer goods without this influencing the measurable economic growth.

A core risk of new technology and change on the labour market is rising inequality. Given the increase in inequality we have already witnessed, as discussed in several books in recent years (Atkinson, 2014, 2015; OECD, 2015; Piketty, 2014; Reich, 2015a; Stigliz, 2012), and the many and varied issues this raises for societies' development, 
Chapter 8 discusses inequality from a multiplicity of angles, including the classical economic inequality, but also discusses wider aspects and the possible consequences of inequality.

One possible consequence of the new types of jobs is that it will change migration. Therefore, Chapter 9 looks into this issue, not least given the many and varied debates on migration in recent years. The outsourcing of jobs to lower wage level countries has been one trend. Another trend in recent years has been the strong movement of migrants and refugees around the world, especially towards the more wealthy societies. The movement of refugees might not be changed by new technology, but migration towards especially low-skilled jobs might be reduced as a consequence of there being fewer of these jobs. In addition, many jobs can now be carried out at home via the internet, implying that migration will perhaps be less interesting than it used to be, which is also due to the fact that migrant workers, except in the highly-skilled part of the labour market, are often at a disadvantage in their ability to get a job. Chapter 9 discusses possible trends and consequences hereof.

Migration has changed societies and welfare states. There have been lengthy debates about whether the overall development of welfare states implies coherent or split societies. Chapter 10 sums up and answers this hypothesis and discusses the overall possible consequences for welfare societies of the changes presented in the book. It also looks into whether we will see coherent or increasingly split societies as a consequence of the changes, while at the same time asking whether we might enter a time where work is no longer as central as it has been historically. This is done by presenting two opposite scenarios - termed the dark side and the bright side. Chapter 10 also presents some suggestions and ways in between the two sides that might help in coping with the expected significant changes to the labour market. Opening up a debate on societies where we work less than in the past might, as an example, be one option as to how to steer the development towards options for having more jobs for more people.

\subsection{DELIMITATIONS}

Naturally, a book such as this cannot cover every aspect of the new technologies and their possible impact in great detail. Naturally, 
some choices have had to be made. Thus, the focus will mainly be on Europe and a selection of EU countries - in such a way, however, that classical welfare regimes are represented, and large and small countries, Northern, Eastern, Western and Southern European countries are also included. However, in some circumstances many European countries are included in order to describe the diversity in the development. Examples from the United States are, to a certain extent, also included in the presentation. The argument that change in technology follows waves, such as Kondratief's long cycles, is not included. For a short introduction to Kondratief, see McCormick et al. (1983).

This book does not try in itself to estimate overall changes in job structures in Europe; instead, by using existing analysis on several EU countries and the United States, it attempts to reflect upon how the overall development might, presumably, look - including how this will possibly have an impact on different professions. Further, it does not try to go into how different understandings of the varieties in labour market or welfare regimes will be challenged by the ongoing restructuring of the labour market and welfare states, but it does reflect upon whether some are more prepared than others to cope with alterations. Nor does it discuss in detail possible new types of jobs and opportunities on the labour market. Whether the destruction of jobs is due to gains and productivity, and the possible impact of an increase in productivity, are also outside the scope of the analysis.

Some argue that at least part of what we are doing when using the internet or other types of IT (such as posting photos and videos) is in fact digital labour, and call it new forms of labour with the same old type of exploitation (Scholz, 2013). Although this has an impact as some types of work, for example photo printing, have been wiped out, the book does not in itself venture into this distinction - not least because partly it is individuals' choice to have a type of communication other than snail mail and landline telephones. Still, this is another indicator of the fact that what we consider to be work has changed, and that what we understand as new opportunities can imply that we take jobs away from others by doing them ourselves.

The possible political voting implication of changes in stable jobs towards more temporary types of jobs and strong insecurity in the labour market is not included in the book, cf. instead Marx (2015). Political rights are one part of social rights. More generally, 
one could argue that indicators of social empowerment also include control over employment contracts and prospects of job mobility (Herrmann, 2012). This book does not probe into these issues and the broader issues of the quality of life; however, employment contracts and organisations in the labour market are part of the analysis of the ongoing restructuring of the labour market. This also includes the work-family life balance which might be threatened, due both to a lack of income and to uncertain working hours. Inequality in happiness is also included; however, how this influences our happiness and ethical understanding of societal development is also outside the scope of the book, cf. instead Leonhard (2016).

Issues such as the option of controlling people, and overseeing what people are doing by registration of their activities on the internet, etc., are also outside the scope of this book, although naturally states will have to look into privacy, possible misuse of information, and pirating activities on the internet. What is happening on the darker side of the internet is also outside the scope of the book, cf. instead Bartlett (2014).

The possible impact on, and development of, monopolies is only included insofar as this is part of the discussion on the influence on the state's ability to finance welfare in the future. The possible geopolitical influence of the development of monopolies and reductions in income-generating activities, for example in Europe, is also outside the direct analysis of the book.

Finally, the possibility that IT-based buying and selling on the stock market in itself can create financial crises due to exaggerated trade is not included, despite the fact that high-frequency trading by IT systems can create disruption. In fact, the desire to reduce such disruption has led France and Italy to implement "a trading tax on each transaction as a disincentive to using computers that launch thousands of trades per second" (Hill, 2015, p. 142).

\section{NOTE}

1. See http://www.oecd.org/economy/germany-boost-investment-and-productivity-fora-stronger-economy-and-more-inclusive-society.htm (accessed 5 April 2016). 